\title{
Evaluation of semiautomated procedure for lymphocyte subset analysis
}

\author{
G J Bryson, R P Keegan, C P Quinn, R J Collins
}

\begin{abstract}
The findings of recent surveys indicate a need for standardisation in lymphocyte subset analysis by flow cytometry. Major areas of concern are the methods used for labelling subsets and the choice of appropriate monoclonal antibodies. A standard dual colour manual whole blood lysis technique for flow cytometry was compared with the recently available Coulter Q-Prep EPICS technique. Overall, there was no significant difference (Student's $t$ test) between the use of anticoagulated blood treated with heparin or EDTA. When normal subjects were examined there was a decrease in the absolute number of $\mathrm{CD3}^{+}$and $\mathrm{Leu}^{-}{ }^{+} I$ $\mathrm{CD8}^{-}$cells and an increase in $\mathrm{CD}^{+}{ }^{+}$and $\mathrm{CD20}^{+}$cells. When human immunodeficiency virus (HIV) antibody positive subjects were examined there was a significant decrease in the absolute number of $\mathrm{CD2}^{+}, \mathrm{CD3}^{+}, \mathrm{CD}^{+}$and $\mathrm{Leu}^{+} / \mathrm{CD8}^{-}$ cells and an absolute increase in $\mathrm{CD}^{+}{ }^{+}$ and $\mathrm{CD}^{+}{ }^{+}$cells. $\mathrm{CD8}^{+}$cells were decreased only with the Cyto-Stat reagents. Occasionally, the Q-Prep did not lyse the red cells efficiently.

While the Q-Prep EPICS system has the potential to standardise and automate the labelling procedures used in $1 \mathrm{ym}$ phocyte subset analysis, further refinement, such as the choice of monoclonal antibodies or alternat:ve preparative reagents, may be required to resolve the cause of the discordant findings between the two approaches.
\end{abstract}

The analysis of lymphocyte subsets using fluorochrome labelled monoclonal antibodies and flow cytometry is now routine clinical practice. Clinical laboratories require a rapid and reliable method that provides both accuracy and precision. Various procedures have consequently been evaluated for the preparation of samples before flow cytometric analysis. These include isolation of lymphocytes on a discontinuous gradient before analysis and whole blood lysis techniques in which the lymphocytes are labelled either before or after red cell lysis. Both directly and indirectly labelled fluorescent polyclonal or monoclonal antibodies have been used. Al of these approaches have been reviewed. ${ }^{1}$ Furthermore, several factors including storage time,,$^{2-4}$ holding temperature, ${ }^{5-7}$ choice of anticoagulant $^{5}$ and transport media ${ }^{8}$ have been shown to affect the yield of $\mathrm{T}$ lymphocytes from blood samples. The advent of AIDS as well as the risk of serious infection by hepatitis B virus has also highlighted awareness of biological safety..$^{910}$ The fixation of biological material is therefore considered necessary to reduce the potential risk of infection, adding another variable to the analysis. When performed manually, the incubation, washing, fixation and centrifugation steps make the preparation of a large number of samples labour intensive.

The Coulter Corporation has developed the semiautomated Coulter Q-Prep EPICS workstation, which has been designed to circumvent the costly labour intensive procedures of manual preparation. The method utilises a whole blood lysis technique, consisting of a short incubation time at room temperatuse with the cells and monoclonal antibodies, followed by red cell lysis and fixation with paraformaldehyde. The entire procedure may be completed in 15 minutes and has several potential advantages over current manual methods, including standardisation of the labelling technique.

In this study we firstly investigated the effect of anticoagulant used on samples prepared by the Q-Prep workstation. Secondly, we compared the results of both normal and HIV antibody positive persons with samples prepared by a whole blood lysis technique in which the red cells were lysed before staining with the monoclonal antibodies.

Methods

Peripheral blood samples from 16 healthy volunteers and from 36 patients who were antibody positive for HIV, ascertained by the Bio-Enzabead HIV ELISA (Organon Teknika Corporation, North Carolina), were collected aseptically by a standard venepuncture technique using evacuated tubes (Becton-Dickinson, Sunnyvale, California). Lithium heparin or EDTA anticoagulants were used.

Fluorochrome-conjugated monoclonal antibodies were used and consisted of two panels. Panel 1 comprised reagents used routinely by this laboratory (table 1 ). They were used in the combinations listed and had been previously titred for optimal staining and stored at $4^{\circ} \mathrm{C}$ before use. Panel 2 comprised Coulter Cyto-Stat reagents (table 1). These reagents were optimised specifically for use with the Q-Prep and consisted of mixtures of two monoclonal antibodies. They were used according to the manufacturer's recommenda- 
Table 1 Directly labelled monoclonal antibodies

\begin{tabular}{|c|c|c|c|}
\hline \multicolumn{2}{|l|}{ Panel 1} & \multicolumn{2}{|l|}{ Panel 2} \\
\hline Monoclonal antibodies & $C D$ & Monoclonal antibodies & $C D$ \\
\hline $\begin{array}{l}\text { Mouse IgG1-FITC } \\
\text { Mouse IgG1-PE } \\
\text { Leu-5b FITC } \\
\text { Leu-12 PE } \\
\text { OKT3 FITC } \\
\text { Leu-16 PE } \\
\text { Leu-3a FITC } \\
\text { Leu-2a PE } \\
\text { Leu-7 FITC } \\
\text { Leu-2a PE } \\
\text { HLe-1 FITC } \\
\text { Leu-M3 PE }\end{array}$ & $\begin{array}{r}- \\
-2 \\
19 \\
3 \\
20 \\
4 \\
8 \\
57 \\
8 \\
45 \\
14\end{array}$ & $\begin{array}{l}\text { Mouse-IgG1 FITC } \\
\text { Mouse-IgG1 PE } \\
\text { Mouse-IgG2a FITC } \\
\text { Mouse-IgG1 PE } \\
\text { B4 FITC } \\
\text { T11 PE } \\
\text { I3 FITC } \\
\text { T3 PE } \\
\text { T8 FITC } \\
\text { T4 PE } \\
\text { T-200 FITC } \\
\text { M-02 PE }\end{array}$ & $\begin{array}{l}-\bar{z} \\
\bar{z} \\
19 \\
2 \\
\frac{3}{8} \\
4 \\
45 \\
14\end{array}$ \\
\hline
\end{tabular}

Panel 1: OKT3 FITC, Ortho Diagnostic Systems; other monoclonal antibodies BectonDickinson, Sunnyvale, California. Panel 2: Coulter, Hialeah, Florida.

tions. Panel 1 was used on the normal volunteers. Both panels were used on the patients.

Q-PREP METHOD

The Q-Prep workstation is a compact $(10 \mathrm{~kg}, 22$ $\mathrm{cm} \mathrm{W}$ by $30 \mathrm{~cm} \mathrm{H}$ by $37 \mathrm{~cm} \mathrm{~L}$ ) unit, consisting of a mixer, a reagent delivery system $\rfloor$ and timing electronics. A transparent door covers the mixing area during operation. The reagents are a matched, three-component system consisting of the following: ImmunoPrep A ( $1.2 \mathrm{ml} / \mathrm{l}$ formic acid, used to lyse red cells); ImmunoPrep B $(6.0 \mathrm{~g} / 1$ sodium carbonate, $14.5 \mathrm{~g} / \mathrm{l}$ sodium chloride, and $31.3 \mathrm{~g} / \mathrm{l}$ sodium sulphate, a leucocyte stabiliser); and ImmunoPrep C (buffered $1 \%$ paraformaldehyde, used as a cell membrane fixative). Both ImmunoPrep $A$ and $B$ have a proprietary stabiliser added. The reagents are stated to be azide free, light insensitive, and stable for 12 months unopened, or for 30 days installed on the workstation.

Q-Prep can be operated in two modes. The first is a 90 second cycle, recommended for high affinity monoclonal antibodies. After the monoclonal antibody has been added to an aliquot of whole blood $(100 \mu \mathrm{l}$ in a $12 \times 75 \mathrm{~mm}$ plastic tube) the tube is placed in the workstation and mixed for 60 seconds. The ImmunoPrep reagents $A, B, C$ are then automatically dispensed and each mixed for 10 seconds, thereby completing the procedure. The second mode is a 35 second cycle, recommended for low affinity monoclonal antibodies, where a 10 minute incubation period at room temperature precedes the addition of reagents. This cycle is identical with the 90 second cycle, except that the initial 60 second mix is reduced to two seconds. In this study the 35 second cycle was used ensuring optimal monoclonal antibody binding via the preincubation step.

The samples from the normal donors were used to investigate the effects of anticoagulant. Tubes containing $100 \mu$ lof whole blood and 10 $\mu \mathrm{l}$ of each monoclonal antibody were vortexed and incubated for either 10 or 20 minutes at room temperature. They were then processed by Q-Prep, held at $4^{\circ} \mathrm{C}$, and analysed within 24 hours.

\section{PRE-LYSIS METHOD}

Whole blood was lysed by mixing $1 \mathrm{ml}$ with 50 $\mathrm{ml}$ of a lysing reagent $(8 \cdot 26 \mathrm{~g} / 1$ ammonium chloride, $0.84 \mathrm{~g} / 1$ sodium bicarbonate, and $0.037 \mathrm{~g} / \mathrm{l}$ tetra sodium EDTA) for 10 minutes at room temperature. All samples were then centrifuged at $600 \times g$ for 10 minutes, the supernate removed, and the cell pellet resuspended in $1 \mathrm{ml}$ of Hanks's Balanced Salt Solution, $\mathrm{Ca}^{++} / \mathrm{Mg}^{++}$free (Gibco, the Dexter Corporation). On all occasions the pellet was resuspended in an appropriate volume to ensure a cell concentration of about $2 \times 10^{7} / \mathrm{ml}$. To tubes containing $10 \mu \mathrm{l}$ of each monoclonal antibody, $50 \mu \mathrm{l}$ of the lysed cell suspension was added. The samples were vortexed, incubated for 20 minutes at $4^{\circ} \mathrm{C}$, followed by the addition of $4 \mathrm{ml}$ of $1 \%$ formaldehyde fixative (May and Baker, Australia) to each tube while vortexing. Samples were held for 10 minutes at $4^{\circ} \mathrm{C}$ and then centrifuged for 10 minutes at $600 \times g$. The supernate was removed and the cell pellet resuspended in $150 \mu \mathrm{l}$ of $0 \cdot 1 \mathrm{M}$ phosphate buffer ( $\mathrm{pH} 7 \cdot 2-7 \cdot 4)$ containing $1 \%$ sodium azide. Samples were held at $4^{\circ} \mathrm{C}$ and analysed within 24 hours.

All samples were analysed on a Coulter EPICS V flow cytometer (Coulter, Hialeah, Florida) using a 5 watt argon laser with an output of $350 \mathrm{~mW}$ at $488 \mathrm{~nm}$. The lymphoid population was gated using forward angle light scatter (FALS) and $90^{\circ}$ light scatter $\left(90^{\circ} \mathrm{LS}\right)$. For each monoclonal antibody evaluated, 3-5 $\times 10^{3}$ lymphocytes were analysed.

To determine the precision and reproducibility of both methods, intrarun and interrun analysis were undertaken. For each method, one sample was separately processed five times and each analysed five times for CD4 positivity.

The osmolality was determined using the freezing point depression method on an Advanced Digimatic Osmometer model 3D11 (Advanced Instruments, Neeham Heights, Massachusetts).

All percentages of positively staining lymphocytes were appropriately adjusted to correct for both non-leucocyte events in the gated population (not stained by CD45; HLe1, Becton-Dickinson) and monocyte contamination (stained by CD14; Leu-M3, BectonDickinson). All results were expressed in absolute numbers derived from the lymphocyte count, which was determined on a Coulter $S$ $\mathrm{IV}^{+}$cell counter (Coulter, Hialeah, Florida).

Comparisons were made between matched pairs of samples prepared by the two methods. Student's $t$ test was used and the $95 \%$ level of confidence taken as the level of significance. On some occasions when a sample was seen to be incompletely lysed, that sample and its matched sample were not included in the statistical analyis.

\section{Results}

Neither the choice of anticoagulant nor the period of incubation produced significantly different results between the two methods of preparation (results not presented).

The 90 LS and FALS dual parameter histograms obtained from samples prepared by Q-Prep indicated acceptable discrimination among the lymphocyte, monocyte, and granu- 
Table 2 Distributions of matched pairs of positive lymphocytes of normal controls processed by pre-lysis method and Q-Prep

\begin{tabular}{|c|c|c|c|c|c|c|c|c|}
\hline \multirow[b]{2}{*}{$C D$} & \multicolumn{4}{|l|}{$E D T A$} & \multicolumn{4}{|l|}{ Lithium heparin } \\
\hline & $P L\left(\right.$ mean $\left.\times 10^{9} / l\right)$ & $Q\left(\right.$ mean $\left.\times 10^{9} / l\right)$ & $t$-test & pvalue & $P L\left(\right.$ mean $\left.\times 10^{9} / l\right)$ & $Q\left(\right.$ mean $\left.\times 10^{9} / l\right)$ & $t$-test & p value \\
\hline $\begin{array}{l}\text { CD2 } \\
\text { CD3 } \\
\text { CD4 } \\
\text { CD8 } \\
\text { Leu-7 } 7^{+} / \mathrm{CD}^{-}- \\
\text {CD19 } \\
\text { CD } 20\end{array}$ & $\begin{array}{l}1.56 \\
1.34 \\
0.90 \\
0.59 \\
0.14 \\
0.20 \\
0.16\end{array}$ & $\begin{array}{l}1.54 \\
1.30 \\
0.88 \\
0.55 \\
0.06 \\
0.28 \\
0.26\end{array}$ & $\begin{array}{r}1.035 \\
2.360 \\
1.339 \\
2.114 \\
3.681 \\
-3.841 \\
-3.985\end{array}$ & $\begin{array}{l}>0.10 \\
<0.05^{\star} \\
>0.20 \\
>0.50 \\
<0.005^{\star} \\
<0.005^{\prime} \\
<0.005 \dagger\end{array}$ & $\begin{array}{l}1.50 \\
1.41 \\
0.86 \\
0.53 \\
0.11 \\
0.20 \\
0.18\end{array}$ & $\begin{array}{l}1.47 \\
1.32 \\
0.84 \\
0.50 \\
0.04 \\
0.28 \\
0.30\end{array}$ & $\begin{array}{r}1.463 \\
3.013 \\
0.747 \\
1.860 \\
6.526 \\
-3.638 \\
-4.658\end{array}$ & $\begin{array}{l}>0.10 \\
<0.01^{\star} \\
>0.40 \\
>0.05 \\
<0.001^{\star} \\
<0.005 \dagger \\
<0.001 \dagger\end{array}$ \\
\hline
\end{tabular}

*Q-prep results significantly less than pre-lysis results.

†Q-prep results significantly greater than pre-lysis results.

Table 3 Distribution of positive lymphocytes of HIV positive patients prepared by either pre-lysis or Q-Prep with panel 1 or panel 2 antibodies

\begin{tabular}{|c|c|c|c|c|c|c|c|c|c|c|c|c|}
\hline \multirow[b]{2}{*}{$C D$} & \multicolumn{4}{|c|}{$P L / Q$ Panel $1(n=36)$} & \multicolumn{4}{|c|}{$P L / Q$ Panel $2(n=16)$} & \multicolumn{4}{|c|}{$Q / Q$ Panel $1 / 2(n=16)$} \\
\hline & $\begin{array}{l}(P L \text { mean } \\
\left.\times 10^{\circ} / l\right)\end{array}$ & $\begin{array}{l}Q(\text { mean } \\
\left.\times 10^{9} / l\right)\end{array}$ & $t$-test & pvalue & $\begin{array}{l}P L(\text { mean } \\
\left.\times 10^{\circ} \mid l\right)\end{array}$ & $\begin{array}{l}Q(\text { mean } \\
\left.\times 10^{9} \mid l\right)\end{array}$ & $t$-test & p value & $\begin{array}{l}\text { Panel } 1 \\
\left(\text { mean } \times 10^{9} / l\right)\end{array}$ & $\begin{array}{l}\text { Panel } 2 \\
\left(\text { mean } \times 10^{9} / l\right)\end{array}$ & $t$-test & p value \\
\hline $\begin{array}{l}\text { CD2 } \\
\text { CD3 } \\
\text { CD4 } \\
\text { CD8 } \\
\text { Leu-7 } 7^{+} / \mathrm{CD}^{-} \\
\text {CD19 } \\
\text { CD20 }\end{array}$ & $\begin{array}{l}1.68 \\
1.62 \\
0.48 \\
1.07 \\
0.15 \\
0.16 \\
0.13\end{array}$ & $\begin{array}{l}1.65 \\
1.56 \\
0.46 \\
1.05 \\
0.11 \\
0.19 \\
0.19\end{array}$ & $\begin{array}{r}2.174 \\
3.791 \\
2.050 \\
0.939 \\
2.988 \\
-2.388 \\
-4 \cdot 490\end{array}$ & $\begin{array}{l}<0.05^{\star} \\
<0.001^{\star} \\
<0.05^{\star} \\
>0.10 \\
<0.005^{\star} \\
<0.005^{\dagger} \\
<0.001 \dagger\end{array}$ & $\begin{array}{l}1.45 \\
1.51 \\
0.46 \\
1.05 \\
\text { ND } \\
0.13 \\
\text { ND }\end{array}$ & $\begin{array}{l}1.44 \\
1.43 \\
0.45 \\
1.00 \\
\text { ND } \\
0.16 \\
\text { ND }\end{array}$ & $\begin{array}{c}0.515 \\
3.378 \\
0.239 \\
3.703 \\
\text { ND } \\
-2.494 \\
\text { ND }\end{array}$ & $\begin{array}{l}>0.50 \\
<0.005^{\star} \\
>0.80 \\
<0.005^{\star} \\
\text { ND } \\
<0.05 \mid \\
\text { ND }\end{array}$ & $\begin{array}{l}1.35 \\
1.58 \\
0.47 \\
1.06 \\
\text { ND } \\
0.13 \\
\text { ND }\end{array}$ & $\begin{array}{l}1.34 \\
1.56 \\
0.48 \\
1.01 \\
\text { ND } \\
0 \cdot 15 \\
\text { ND }\end{array}$ & $\begin{array}{l}0.409 \\
1.446 \\
-1.104 \\
3.960 \\
\mathrm{ND} \\
-1.526 \\
\mathrm{ND}\end{array}$ & $\begin{array}{l}>0.50 \\
>0.50 \\
>0.20 \\
<0.005 \ddagger \\
\mathrm{ND} \\
>0.10 \\
\mathrm{ND}\end{array}$ \\
\hline
\end{tabular}

PL, pre-lysis method; Q, Q-Prep method.

$\star Q$-Prep results significantly less than pre-lysis results.

tQ-Prep results significantly greater than pre-lysis results.

$\ddagger$ Panel 2 results significantly less than panel 1 results.

locyte populations. The Q-Prep preparation caused a slight increase in FALS, about 10 channels, when compared with the pre-lysis method, but this did not adversely affect the resolution of the lymphocyte population.

COMPARISON OF PRE-L YSIS METHOD WITH Q-PREP A comparison was made between the 16 normal samples prepared by the pre-lysis method and the same samples prepared by Q-Prep (table 2). The results indicated that the Q-Prep method produced slightly lower percentages for $\mathrm{CD}^{+}$, $\mathrm{CD}^{+}, \mathrm{CD}^{+}, \mathrm{CD}^{+}$and the Leu- $7^{+} / \mathrm{CD}^{-}$ subset and slightly higher percentages for $\mathrm{CD}_{19}{ }^{+}$and $\mathrm{CD}_{20}{ }^{+}$. At the $5 \%$ level of significance, however, differences were recorded only for $\mathrm{CD}^{+} \quad(\mathrm{p}<0.01), \quad \mathrm{CD}^{+} 9^{+}$ $(\mathrm{p}<0.005), \mathrm{CD}^{+} 0^{+}(\mathrm{p}<0.005)$ and the Leu$7^{+} / \mathrm{CD}^{-}$subset $(\mathrm{p}<0.001)$.

\section{HIV ANTIBODY POSITIVE PATIENTS}

Comparisons were made between 36 samples prepared by the pre-lysis method and the same samples prepared by the Q-Prep method using panel 1, and 16 samples using both panels of monoclonal antibodies (table 3). Significant differences were recorded for $\mathrm{CD} 2^{+}$ $(\mathrm{p}<0.05), \quad \mathrm{CD}^{+} \quad(\mathrm{p}<0.001), \quad \mathrm{CD}^{+}$ $(\mathrm{p}<0.05), \quad$ Leu $7^{+} / \mathrm{CD}^{-} \quad(\mathrm{p}<0.005)$,

Table 4 Precision of both methods determined by percentage of CD4 lymphocytes

\begin{tabular}{lccccccccccc}
\hline \multicolumn{10}{c}{ Pre-lysis } & \multicolumn{11}{c}{ Q-prep } \\
\hline Intrarun: & & & & & & & & & & \\
Sample & 1 & 2 & 3 & 4 & 5 & 1 & 2 & 3 & 4 & 5 \\
Mean & 39.8 & 40.4 & 40.6 & 40.8 & 39.8 & 39.2 & 40 & 40 & 40 & 39.8 \\
1 SD & 0.98 & 0.80 & 1.00 & 0.75 & 0.97 & 0.75 & 1.09 & 0.63 & 0.63 & 0.75 \\
oCV & 2.5 & 2.0 & 2.5 & 1.8 & 2.4 & 1.9 & 2.7 & 1.6 & 1.6 & 1.9 \\
Interrun: & & & & & & & & & & \\
Mean & 39.4 & 40.6 & 39.8 & 41.0 & 40.6 & 39.2 & 39.8 & 40 & 39.6 & 40.4 \\
1 SD & 1.01 & 0.49 & 0.98 & 0.89 & 0.49 & 0.75 & 0.98 & 0.63 & 0.80 & 0.45 \\
o CV & 2.6 & 1.2 & 2.5 & 2.2 & 1.2 & 1.9 & 2.5 & 1.6 & 2.0 & 1.1 \\
\hline & & & & & & & & & & &
\end{tabular}

$\mathrm{CD}^{+}{ }^{+}(\mathrm{p}<0.001)$ and $\mathrm{CD}^{+} 9^{+}(\mathrm{p}<0.05)$ when using panel 1 . The results differed significantly for $\mathrm{CD}^{+} .(\mathrm{p}<0.005), \mathrm{CD}^{+}$ $(p<0.005)$, and $\mathrm{CD}_{19}{ }^{+}(\mathrm{p}<0.05)$ when using panel 2. A comparison between the methods of preparation and panels of monoclonal antibodies indicated that the batch of Cyto-Stat CD8 reagent used and not the preparation reagents was responsible for the decreased CD8 result.

The intrarun and interrun results, which indicate a high precision for both approaches, are presented in table 4.

The osmolality of Immunoprep A was $33 \mathrm{~m}$ osmol/kg, Immunoprep B $1065 \mathrm{~m} \mathrm{osmol} / \mathrm{kg}$, and Immunoprep C $280 \mathrm{~m}$ osmol/ $\mathrm{kg}$. The values are the mean obtained from three separate determinations.

\section{Discussion}

The purpose of first analysing the controls was to establish an acceptable standardised procedure using the Q-Prep workstation, so that subsequent abnormal samples would not be unduly affected by the choice of either the anticoagulant or incubation times. Coulter recommends the use of EDTA as the anticogulant and suggests that samples should be processed as soon as possible after collection. Lithium heparin, however, is frequently used as the anticoagulant of choice for surface membrane antigen phenotyping, especially if there is a delay between collection and processing. This does occur when samples are referred from regional areas to a central laboratory. In our study the use of either EDTA or lithium heparin as the anticogulant did not significantly affect the results, indicating that lithium heparin would be a suitable alternative to EDTA.

A comparison of the Q-Prep method with the 
pre-lysis method indicated that $T$ cell numbers were decreased and $B$ cell numbers increased in the Q-Prep preparations of both groups of samples with either panel of monoclonal antibodies. No significant differences in the physical or staining characteristics could be shown when comparisons were made between normal and HIV antibody positive patients. In a number of cases the discrepancies in $B$ and $T$ cell numbers were only slight, but the results for $\mathrm{CD}_{3}^{+}, \mathrm{CD}_{19}{ }^{+}, \mathrm{CD}_{20}{ }^{+}$and the Leu-7/ $\mathrm{CD}^{-}$subset differed significantly (table 2 ). Leu- $7^{+}$was decreased in both the percentage of positive cells and fluorescence intensity. This loss was demonstrable in both the $\mathrm{CD}^{+}$and $\mathrm{CD}^{-}$subsets. Monoclonal antibodies staining the natural killer cell population, such as Leu11 (CD16) and Leu-19, need to be investigated to determine whether an accurate enumeration of this cell population can be achieved when using Q-Prep. While it is acknowledged that the Coulter Corporation recommends only the use of their own reagents with the workstation, other antibody combinations will no doubt be used. The precise reason for the differences obtained between the two methods obviously requires further investigation. The differences may at least in part be due to either a selective loss of $T$ cells or some $T$ cell epitopes with the Q-Prep method, possibly occurring in the lysis step. Alternatively, there may be selective loss of B cells with the pre-lysis method, possibly during the washing steps. Both phenomena may contribute with the cumulative effect becoming significant. The intrarun and interrun study indicates that the differences seen are not explained by the analytical imprecision associated with the methods.

In support of the suggestion that the Q-Prep procedure may contribute to the discrepancies is our finding of an increase in lymphocyte size as determined by the increase in FALS channel number. As part of an investigation of this we determined the osmolality of the Immunoprep reagents and found that Immunoprep $A$ was noticeably hypotonic, with Immunoprep B noticeably hypertonic, and Immunoprep $C$ essentially isotonic. It is distinctly possible that the counter effect of Immunoprep $B$ on Immunoprep $A$ is not sufficient to return the lymphocyte mean corpuscular volume to normality in the given time period of preparation, resulting in an increase in FALS. Further work is required to ascertain the consequences of this magnitude of hypo-hypertonic manipulative procedures on lymphocyte surface structures or cellular integrity, which may affect lymphocyte subset enumeration.

The increase in FALS recorded in this study contributed to the excellent discrimination between the lymphoid population and red cell debris when red cell lysis was complete. About $8 \%$ of the 328 samples processed in this study, however, were incompletely lysed, resulting in heavy red cell contamination of the lymphoid population and invalidating the results. An incorrect volume of lysing reagent being dispensed, either as a consequence of air bubbles in the tubing of the delivery system, or droplets of lysing reagent adhering to the top of the sample tube, even after mixing, was observed to be the cause. The delivery system of the latest Q-Prep model (not used in this study) has been modified to ensure that the correct volume of reagents is dispensed.

The time required for flow cytometric analysis was almost doubled due to the decrease in final cell concentration. This can be avoided by simply adding a centrifugation step and resuspending the cell pellet in a smaller volume, but this will increase the overall specimen processing time and introduce a potential step for cell loss.

The recommended fixation time for Q-Prep processing is only 10 seconds. The fixative used was $1 \%$ paraformaldehyde which would have a final concentration of $0.1 \%$ when added to the sample tube. Although this concentration may be sufficient to fix the cell membrane of leucocytes, extra- and intracellular HIV may not be inactivated within this time period. ${ }^{9}$ The treatment of cells infected with HIV with paraformaldehyde at concentrations of $0.1 \%$ or greater for two hours at room temperature has been reported to render the cells noninfectious, ${ }^{11}$ Further studies are necessary to investigate the minimum incubation period required to render cells biologically safe. It has been previously shown that $1 \%$ formalin would reduce reverse transcriptase activity, but complete intracellular inactivity was not achieved after two hours of exposure. ${ }^{12}$

We believe that the Q-Prep workstation is potentially useful for the rapid preparation of lymphocytes for immunofluorescence analysis. The system has several advantages, including standardisation of preparation, a potentially reduced biohazard risk (due to the decreased number of manipulative steps) compared with conventional procedures, and substantially reduced labour costs. Several potential disadvantages, however, also need to be considered. Not all monoclonal antibodies can be used with the system; significant differences in the incidence of positive cells can be shown compared with established manual whole blood techniques; and the minimum time required to render cells biologically safe needs to be established. Further refinement in the technique will no doubt nullify some of these preliminary findings.

We thank Coulter Australia Pty-Ltd for the opportunity to assess the O-Prep EPICS workstation and the Cyto-Stat reagents in this study, and Mrs C Ruetschi for the preparation of the manuscript.

1 Muirhead KA, Wallace PK, Schmitt TC, Frescatore RL, Franco JA, Horan PK. Methodological considerations for Franco JA, Horan PK. Methodological considerations for implementation of lymphocyte subset analysis in a clinical

2 Weiblen BJ, Debell K, Giorgio A, Valeri CR. Monoclonal aeiblen BJ, Debell K, Giorgio A, Valeri CR. Monocional
antibody testing of lymphocytes after overnight storage. J Immunol Methods 1984;70:179-83.

3 Weiblen BJ, Debell K, Valeri CR. "Acquired Immunodeficiency" of blood stored overnight. N Engl J Med 1983;309:793.

4 Nicholson JKA, Jones BM, Cross DG, MacDougal JS. Comparison of $\mathrm{T}$ and $\mathrm{B}$ cell analysis on fresh and aged blood. J Immunol Methods 1984;73:29-40.

5 Thornthwaite JT, Rosenthal PK, Vazquez DA, Seckinger 
D. The effects of anticoagulant and temperature on the measurements of helper and suppressor cells. Diagnost Immun 1984;2:167-74.

6 Shield CF, Mariett P, Smith A, Gunter L, Goldstein G. Stability of human lymphocyte differentiation antigens when stored at room temperature. J Immunol Methods 1983;62:347-52.

7 Grunow JE, Lubet RA, Ferguson MJ, Gaulden ME. Preferential decrease in thymus dependent lymphocytes during storage at $4^{\circ} \mathrm{C}$ in anticoagulant. Transfusion 1976;16:610-

8 Hensleigh PA, Waters VB, Herzenberg LA. Human T lymphocyte differentiation antigens. Effects of blood sample storage on Leu antibody binding. Cytometry 1983;3:453-5.
9 Martin LS, McDougal JS, Loskoski SL. Disinfection and inactivation of the human $T$ lymphotropic virus type
III/lymphadenopathy-associated virus. $J$ Infect Dis 1985;152:400-3.

10 Lifson JD, Sasaki DT, Engleman EG. Utility of formaldehyde fixation for flow cytometry and inactivation of the AIDS associated retrovirus. J Immunol Methods 1986;86:143-9.

11 Martin LS, Loskoski SL, McDougal JS. Inactivation of human T-lymphotropic virus type III/lymphadenopathy-associated virus by formaldehyde-based reagents. App Environ Microbiol 1987;53:708-9.

12 Spire B, Barre-Sinoussi F, Montagnier L, Chermann JC. Inactivation of lymphadenopathy associated virus by chemical disinfectants. Lancet 1984;ii:899-901. 